\title{
Inactivation of allergens and toxins
}

\section{Piero Morandini}

Dept. of Biology, University of Milan, and CNR, Institute of Biophysics, Via Celoria 26, 20133 Milano, Italy

Plants are replete with thousands of proteins and small molecules, many of which are species-specific, poisonous or dangerous. Over time humans have learned to avoid dangerous plants or inactivate many toxic components in food plants, but there is still room for ameliorating food crops (and plants in general) in terms of their allergens and toxins content, especially in their edible parts. Inactivation at the genetic rather than physical or chemical level has many advantages and classical genetic approaches have resulted in significant reduction of toxin content. The capacity, offered by genetic engineering, of turning off (inactivating) specific genes has opened up the possibility of altering the plant content in a far more precise manner than previously available. Different levels of intervention (genes coding for toxins/allergens or for enzymes, transporters or regulators involved in their metabolism) are possible and there are several tools for inactivating genes, both direct (using chemical and physical mutagens, insertion of transposons and other genetic elements) and indirect (antisense RNA, RNA interference, microRNA, eventually leading to gene silencing). Each level/strategy has specific advantages and disadvantages (speed, costs, selectivity, stability, reversibility, frequency of desired genotype and regulatory regime). Paradigmatic examples from classical and transgenic approaches are discussed to emphasize the need to revise the present regulatory process. Reducing the content of natural toxins is a trade-off process: the lesser the content of natural toxins, the higher the susceptibility of a plant to pests and therefore the stronger the need to protect plants. As a consequence, more specific pesticides like $\mathrm{Bt}$ are needed to substitute for general pesticides.

\section{Contents}

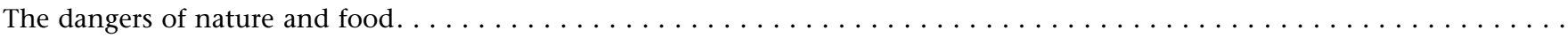

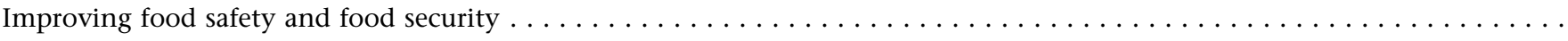

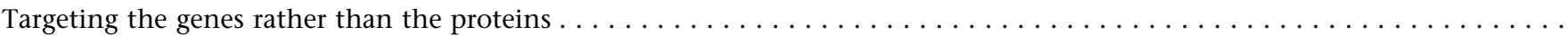

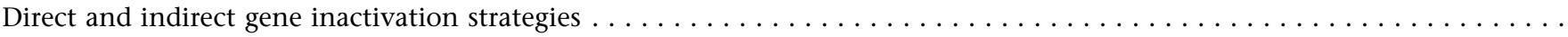

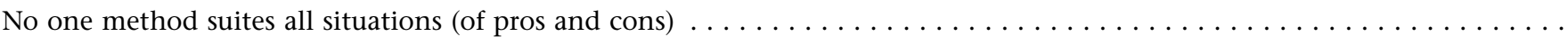

Examples of inactivation of toxins in transgenic plants . 


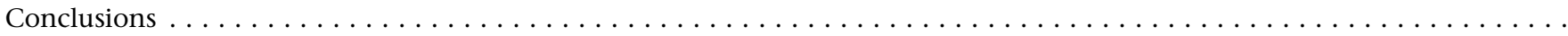

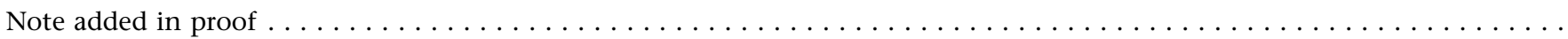

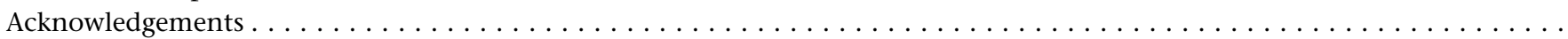

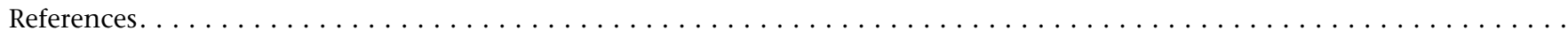

\section{The dangers of nature and food}

Toxic substances abound in living beings, plants included. Humans use plants (or products made from them) as a source of food, fiber, fuel, tools or drugs and therefore are constantly exposed to toxins and allergens of plant origin. The plant world can thus be viewed as a 'minefield'. A short walk both in cultivated fields and wild areas in many places in Italy, for which I have some experience, and more generally everywhere in the world, allows one to meet plants which have caused poisoning or even fatalities in humans or animals (see some examples in Table 1). For instance, castor bean (Ricinus communis) is common in southern Italy and produces ricin, a poison among the most potent known to man. The lethal oral dose in humans is approximately eight beans; even half a bean was enough to cause death [1]. Other highly toxic encounters in Mediterranean countries are oleander (Nerium oleander) and most plants in the Ranunculaceae, Scrofulariaceae and Solanaceae (nightshade) families. For references on common toxic plants in Italy [2]; for North America [3]; for a general treatise [4]; for a recent compilation [5]; for a website [6]. The common names for several members of the
Solanaceae are quite explicit in their message: angel's trumpet or devil's weed (Datura stramonium), the apple of Sodom (Solanum sodomeum), bittersweet nightshade or poisonberry (Solanum dulcamara), black nightshade or devil's little tomatoes (Solanum nigrum) and deadly nightshade (Atropa belladonna). Some of the fruits or flowers are quite attractive in appearance and therefore become more dangerous for people raised in urban settings and who are unaware of the risks, children in particular, for example [7-9]. One author suggests that 'about 2\% of plant species can severely poison people who happen to ingest them', with alkaloids being the major cause [10]. Some toxins are quite widespread among plants, like cyanogenic glucosides, which are reported in at least 2500 different species [11]. Many toxic plants are weedy, wild plants which need not human's intervention to survive.

Likewise, many crops have dangerous substances (Table 1), some in edible part and some in organs not used as food. For instance potato tubers or ripe tomato fruits usually have low levels of glycoalkaloids, but leaves, diseased tubers and fruits (a small berry) of potato or leaves and immature fruits of tomato are more

TABLE 1

Examples of wild and crop plants with toxic substances and their effects

\begin{tabular}{|c|c|c|c|c|}
\hline Common name & Latin name & Toxic substance $^{a}$ & Effect $^{\mathbf{b}}$ & Dose $^{c} \mid$ content $^{d}$ \\
\hline Giant fennel & Ferula communis & Prenylated coumarins & Lethal & \\
\hline Jimson weed & Datura stramonium & Atropine (and other alkaloids) & Lethal & 100 seeds $\mid 0.1 \mathrm{mg} / \mathrm{seed}$ \\
\hline Tobacco & Nicotiana tabacum & Nicotine & Lethal & $1 \mathrm{mg} / \mathrm{kg} \mid 3-6 \%$ \\
\hline Apple of sodom & Solanum sodomeum & Solasonine, solanidine & Toxic & $30 \mathrm{mg} / \mathrm{kg} \mid 0.3 \mathrm{mg} / \mathrm{g}$ \\
\hline Castor bean & Ricinus communis & Ricin/ricinoleic acid & Lethal & Half a seed \\
\hline Pepper & Capsicum spp. & Capsaicin & Lethal & |0-2 mg/g \\
\hline Tomato & Solanum lycopersicum & Tomatine & Toxic & \\
\hline Potato & Solanum tuberosum & Solanine & Lethal & |3-6 mg/kg \\
\hline Cassava (Yucca) & Manihot esculenta & Cyanogenic glucosides & Paralysis-stunting & $15-400 \mathrm{mg} \mathrm{HCN} / \mathrm{kg}$ \\
\hline Soybean & Glycine max & Protease/amylase inhibitors & Toxic & \\
\hline Almond & Prunus dulcis & Cyanogenic glucosides & Lethal & 20 seeds $29 \mathrm{mg} / \mathrm{kg}$ \\
\hline Brussel sprouts & Brassica oleracea & Glucosinolates & Lethal-goiter & $1-2 \mathrm{mg} / \mathrm{g}$ \\
\hline Cotton & Gossypium hirsutum & Gossypol & Cardio/hepatotoxic & $0.3-3 \mathrm{mg} / \mathrm{kg} / 10 \mathrm{mg} / \mathrm{g}$ \\
\hline Vetch & Lathyrus sativus & Oxalyl-diaminopropionic acid & Neurotoxin/paresis & |0.3-3.2\% \\
\hline Lima bean & Phaseolus lunatus & Cyanogenic glucosides & Lethal & $2-3 \mathrm{mg} \mathrm{HCN} / \mathrm{kg}$ \\
\hline Poppy & Papaver somniferum & Morphine & Lethal & $100 \mathrm{mg} \mid 10 \mathrm{mg} / \mathrm{g}$ \\
\hline Bamboo & Several species & Cyanogenic glucosides & Toxic & |1-8 g HCN/kg \\
\hline
\end{tabular}

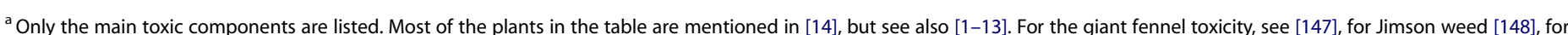
pepper [149]. Many other toxic substances can often contaminate plants or food, but are not considered in this list.

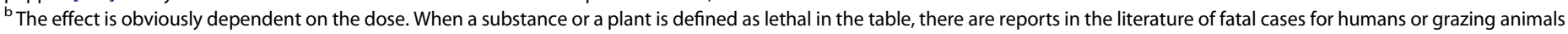
(e.g. [147]). For other examples of toxicity in animals, see http://www.ansci.cornell.edu/plants/ (plant poisonous to livestock and other animals).

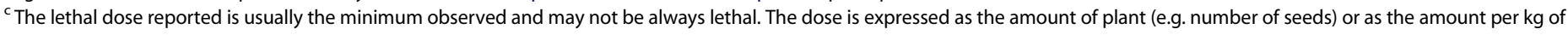
body weight able to cause the effect.

${ }^{d}$ The content refers to the main active principle causing the toxic effect and it is expressed per plant part or weight. 
toxic. Cases of severe poisoning, sometimes fatal, are reported in the literature for several of the edible plants listed in Table 1 (e.g. $[12,13]$; for a compilation [14]).

Most of the toxic substances in plants are known to men since time immemorial and were identified by modern science according to their chemical characteristics (alkaloids, glucosides, aminoacids, proteins, lipids, etc.). Their toxicology and mode of action have been described (for a comprehensive compilation see $[4,5]$ ). Although some (e.g. digitoxin) have a long history of use as pharmaceuticals and are still used today, most have been abandoned because of the short interval between therapeutic and toxic dose.

The ability of humans to survive and thrive depends on their capacity to recognize and avoid or inactivate most of these toxic compounds. Especially for plants used as food, this is achieved by a combination of proper storage and processing (e.g. maceration and fermentation) among which cooking is the most prominent for its major effect of heat inactivation. Knowledge in this context can be likened to a precise map handed down from generation to generation through culture and education, warning of the dangers of the minefield, while technology becomes similar to a metal detector to reveal, avoid or inactivate toxic substances. Knowledge and technology buffer us from the toxic effect of nature and allow a far wider spectrum of plants or plant parts to be used to our benefit than those 'naturally' available. The widespread belief in the superior goodness of nature and the evil of manipulations by human is causing harm and death (e.g. [15-17]).

Cultivated plants seem to have fewer toxins than their wild relatives, as the result of selection for better-tasting plants [18]. For example, the wild potato Solanum acaule has three times more glycoalkaloids than cultivated potato and is more toxic [19-21]. Cultivated Brassicaceae (cabbage, broccoli and cauliflower), when compared to wild species, have less glucosinolates, a major class of secondary metabolites [22,23] and this affects the survival of herbivore insects and their parasitoids [24,23]. The wild bean Phaseolus lunatus contains about three times cyanogenic glucosides when compared to the cultivated bean [25]. Wild and cultivated beans have different levels of antinutritional factors [26]. Cyanogenic glucosides in white clover (a forage crop) act as a deterrent against herbivores [27], but cultivars devoid of cyanogenic glucosides have been bred to obtain better palatability for grazing animals. Similar reductions have been reported for other crops [28]. The issue is complicated by the effect of the environment and pest pressure [29]. Whether this is a general rule remains to be demonstrated, but it seems an acceptable hypothesis and might contribute to the general susceptibility of crop plants to pests. Nevertheless, the point remains that humans can clearly tolerate at least low levels of toxins in their diet without ill effects. In fact, the ability to safely consume a low level of toxins has been a key element in the survival of all omnivores. The most appealing explanation for the observed crop-wild differences is that humans selected loss of function mutations leading to a reduced toxin content during the domestication process on the basis of feeding 'tests'. Most presumably it was a long process of trial and error (or trial and death). At least in one case it seems that not only the overall quantity of toxic glucosinolates is reduced, but also that inducibility by wounding is lost in the cultivated species [23].

Thus many crops still produce the same kind of toxins as their wild relatives, albeit in lower quantity, at least in edible parts. This means that the biosynthetic capacity is there. Indeed sometimes crops are fatal for humans $[12,13,30]$. Moreover, toxin content might increase spontaneously or during the breeding process, the so-called 'unintended effects'. Cases are known where commercial varieties caused health problems for this reason: rashes from celery [31,32], vomiting, stomach cramps, diarrhea or collapse from zucchini [33,34], potato [35] and bottle gourd [36]. Therefore testing for known toxins is routinely performed in crops known to contain toxic compounds, irrespective of the breeding method used. A problem relevant both to the developing and developed world is mycotoxin contamination of foodstuffs. Mycotoxins are not actually produced by plants, but are a byproduct of fungal growth on plants or foods. While there are several strategies (both conventional and transgenic) to control mycotoxins, this is outside the scope of my review. Other authors discuss mycotoxins in this issue (W. Parrot, B. Chassy).

\section{Improving food safety and food security}

The presence of toxic substances is still problematic for a few crop plants, which might be ameliorated by a further reduction, as well as for wild plants, in those cases for which a rapid domestication process might be desirable, such as for some biofuel crops [37]. To give a perception of the relevance of crop amelioration in economical as well as human terms, I provide three examples: rapeseed, cassava and cotton.

Rapeseed is widely grown and the annual production in 2007 was $50 \mathrm{Mt}$. The seeds are used mainly for oil production. After extraction, the resultant meal (35 Mt/year) is a good source of protein for animal feed, but its use is often limited by the amount of glucosinolates that can be ingested because of their toxicity. Glucosinolates themselves are not toxic, but upon cell disruption, they are hydrolyzed by plant myrosinases (specific esterases) and their hydrolysis products have been shown to be deleterious to rat, pig, poultry, rabbit, cow, sheep and fish, with effects on health, growth, productivity and reproduction (reviewed in [38]). In several cases, high-level intake results in increased mortality. Part of the negative effects on animals can be reduced by iodine supplementation, because some of the glucosinolates hydrolysis products interfere with thyroid hormone production. Classical breeding was used to create varieties low in glucosinolates: the so-called 'double zero' varieties are low in (but not devoid of) both erucic acid and glucosinolates. Also several treatments are available to reduce glucosinolate content [38]. Processing like heat inactivation further reduces the toxicity of glucosinolates, but also reduces lysine availability and thus the quality of the feed [39]. Thus genetic engineering gives a possibility of improving the meal through selective removal/reduction of glucosinolates in seeds beyond the reductions already obtained by breeding. The problem of toxicity might be less relevant in developed countries where most varieties have already a reduced glucosinolate content, but further improvements at the genetic level can translate into increased feed utilization efficiency, even in developed countries, making intensive agriculture more sustainable.

Cassava is a staple food for around 700 million people in the world, mainly Africa and Latin America. The starchy tuberous roots are poor in protein and contain varying amounts of two cyanogenic glucosides (linamarin and lotaustralin) which can be converted to HCN upon hydrolysis of the glucoside. Chronic 
exposure to sublethal levels of $\mathrm{HCN}$ is responsible for konzo (irreversible paralysis of legs [40-42]), goiter and cretinism, stunting of children [42] and possibly Tropical Ataxic Neuropathy [43]. Some of these effects are exacerbated by diets poor in iodine and/or protein. On the history and sufferings connected to goiter due to iodine deficiency, I recommend the book by Hetzel [44]. Both bitter and sweet cassava (with a reduced content of cyanogenic glucosides) are available [45], but the preference of consumers and farmers depends also on traits such as cooking quality, starch texture and resistance to disease. Therefore the availability of plants combining certain characteristics with reduced cyanogen content might be better achieved by transgenesis rather than breeding. Given the rising consumption of cassava, especially in Africa [46] there is the case for improving varieties as well as education on the methods to process cassava tubers to remove cyanogens [46].

The third example is cotton, a crop primarily grown for fiber with an annual production in the range of $25-28 \mathrm{Mt}$ of fiber in recent years. Interestingly, for each $\mathrm{kg}$ of fiber the plant produces $1.65 \mathrm{~kg}$ of seed (41-46 Mt/year) which contains $21 \%$ oil and $23 \%$ protein. The meal left after oil extraction contains high-quality protein (8-10 Mt/year), but it is unsuitable for consumption by monogastric animals, humans included, because of the presence of gossypol, a cardio- and hepato-toxic terpenoid [47]. It is therefore used as feed for ruminants, which are less sensitive to gossypol, either as meal after oil extraction or more rarely as whole seeds. Costly chemical, biological and physical procedures (see [48] for some references) are used to remove gossypol from cottonseed products to allow their use as food for non-ruminant animals, including solvent extraction with different solvents, ferrous sulfate or calcium hydroxide treatment, microbial fermentation and mechanical processing. It is clear that the development of varieties without gossypol would completely eliminate the need for gossypol removal and could potentially satisfy the daily protein requirement for half a billion people. A glandless cotton mutation was discovered in 1954 and immediately attracted the attention because gossypol accumulates in epidermal glands, located in seeds and aerial plant parts. Several commercial glandless varieties were developed by conventional breeding but they turned out to be extraordinarily susceptible to several insect pests, presumably because they lack protective terpenoids $[49,50]$.

\section{Targeting the genes rather than the proteins}

The overwhelming majority of toxins are either protein themselves or are synthesized by proteins. The dogma of molecular biology states that 'DNA makes mRNA and mRNA makes protein'. This is normally represented as: Gene $\rightarrow$ mRNA $\rightarrow$ Protein. If we target the gene or the mRNA coding for a certain protein, then we end up not making the protein at all or making a nonfunctional protein. Therefore, the most sensible approach to reduce/inactivate a toxin in a living being is targeting the gene coding for (i) the toxin (if this is a protein synthesized through mRNA/ribosomes), (ii) a component of the specific machinery/pathway responsible for its production/accumulation (as is the case for toxic metabolites) or (iii) a regulator of the expression of the toxin, either directly (for a toxic protein) or indirectly (if it is a metabolite). Other strategies are the pharmacological or physical inactivation of the protein (e.g. by heat through cooking and food processing) or the stimulation of its degradation, but these strategies will not be dealt with here. I shall focus on inactivation at the gene/mRNA level as a safe and cheap alternative. The power of this approach is that mutations are inherited and usually quite stable. All the progeny of a plant with a disrupted gene will carry the same inactive allele. This implies that protein inactivation through gene inactivation is a once-for-all approach and needs not to be repeated at each generation or harvest. In a few cases, mutations could revert to the original status, but this is a spontaneous process whose frequency depends on the type of mutation. Selecting the appropriate mutation can make the reversion frequency extremely low. The next question is: how it is possible to inactivate a gene or its corresponding mRNA?

\section{Direct and indirect gene inactivation strategies}

Mutations arise spontaneously in any organism and by several means. Some of the causes are inevitable, such as background radiation, the endogenous production of reactive oxygen species or the mutagenic effect of DNA replication and cell division, while others can be induced or strengthened by environmental conditions. Mutation frequency can be enhanced for experimental purposes by various treatments: UV, $\mathrm{X}$ - and $\gamma$-rays, chemical mutagens and mitogens (indirectly), just to name a few. Mutants arise for instance because transposons can move around and 'jump' into genes. Similar results can be obtained by natural transposons or T-DNA/engineered transposons [51-54]. Genes have been inactivated through mutation (broadly defined as base changes, insertion or deletion) all the time. A mutation can involve just a single base or entire chromosomes. The importance of this process is particularly evident during domestication whereby the expression of certain genes was altered. For instance, loss of shattering, a trait of great importance in agriculture, is attributed to a disruption in the development of the abscission zone between grains and pedicles $[55,56]$; for more examples, see $[57,58]$. Many mutations involved in domestication are recessive, consistent with a loss of function and are deleterious in the wild (see contribution by P. Raven in this issue). Whether a similar phenomenon applies to the reduction in toxin content that happened during domestication, it is too early to tell for the lack of molecular data, but it seems quite a plausible mechanism.

Mutations resulting in inactivation of a protein can be classified into two broad categories (Fig. 1): mutations in the targeted gene and mutations involving another gene, but which affect the targeted gene via an RNA intermediate. The first class of mutations strike at the gene itself (box in Fig. 1a) thereby compromising the ability to produce a functional/stable mRNA or affecting the functionality or stability of the corresponding protein. The other class (RNA-mediated, Fig. 1b) interferes with the expression of the target gene by means of a double-stranded RNA (dsRNA), but leaves the gene sequence unchanged. This second class is collectively referred to as post-transcriptional gene silencing (PTGS), different variants of which are possible (antisense, RNAi, miRNA, hpRNA, etc.) and often involve epigenetic changes [59-61]. To be precise, the direct inactivation of a gene coding for a regulator (e.g. transcription factor) of a metabolic pathway is a protein-mediated strategy and therefore should be classified as an 'indirect gene inactivation', but for the sake of simplicity it will be treated as a direct gene inactivation strategy, because the targeted gene is directly inactivated. 


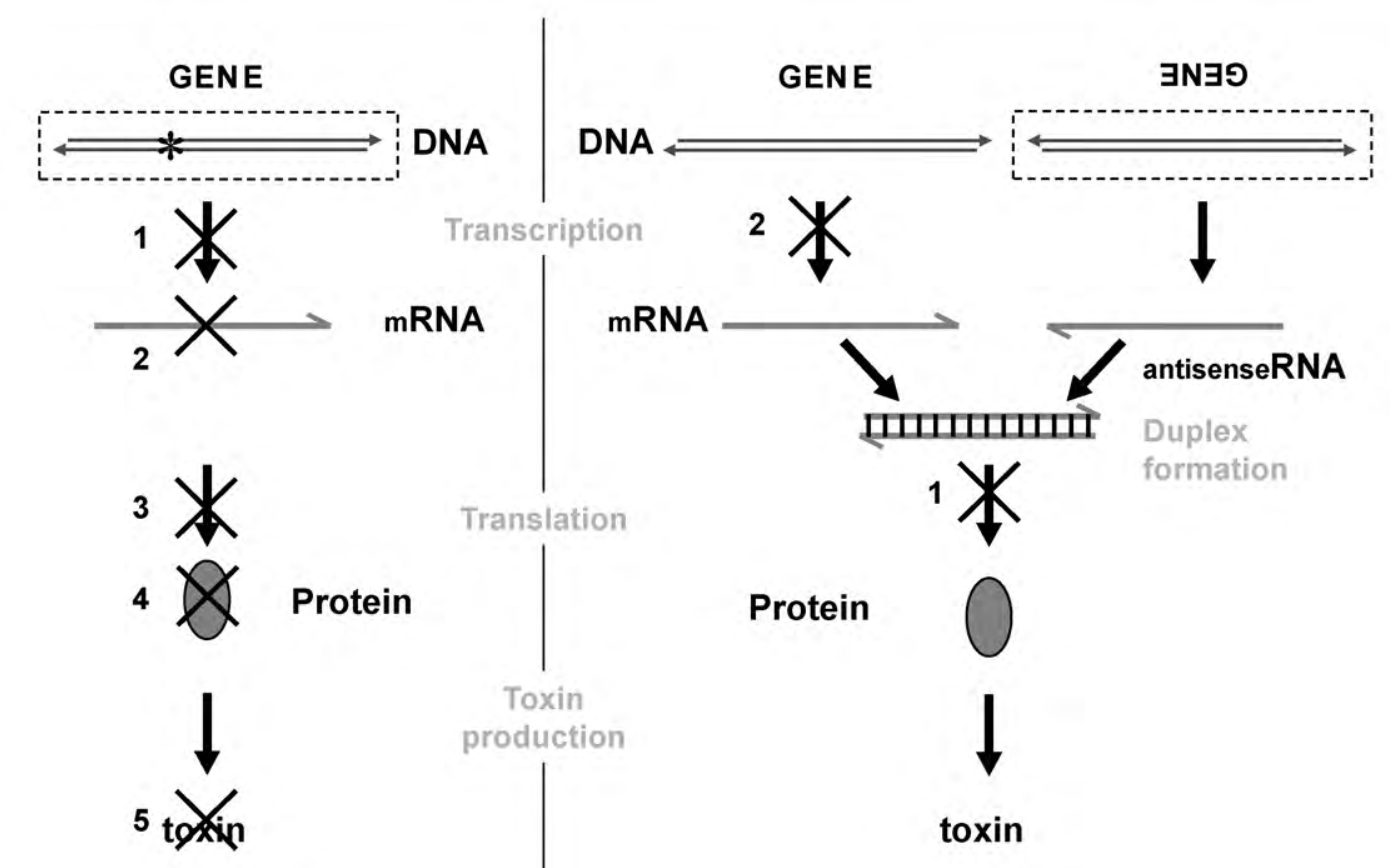

(b) Indirect (RNA-based) inactivation

\section{(a) Direct gene inactivation}

\section{FIGURE 1}

Classification of gene inactivation strategies. Strategies can be broadly assigned to either to (a) direct or (b) indirect category. The former indicates all those situations where the gene itself (within dashed box) is inactivated by the mutation, which is depicted as an asterisk at the DNA level and representing any change in the DNA sequence; large $\times$ represent all the potential levels where the inactivation may reveal itself: transcription (1), mRNA processing or stability (2), translation (3), protein folding or stability (4) or function (5). Indirect strategies (b) leave the original gene intact, but introduce another gene (dashed box) which produces an RNA molecule complementary to the mRNA of the gene that is going to be silenced. For this reason the introduced gene is depicted in the antisense orientation and the RNA produced is called antisenseRNA, often abbreviated in asRNA. The mRNA (sense) and the antisenseRNA pair together forming a duplex (dsRNA) which inhibits translation directly (1) or prevents transcription (2, indirectly, at the chromatin level, via the production of small RNAs).

The different methods to obtain a mutant are listed in Table 2, together with advantages/disadvantages of each method. It is noteworthy to stress that different methods might end up exactly in the same result - lack of a (functional) protein - and could be mediated by the same or a similar change at the DNA level, irrespective of the agent performing the modification (be it a human being or a bacterium or the plant itself) or the method by which the mutation is produced. It is therefore hard or impossible to distinguish natural/non-natural mutations (see contributions by W. Arber and by W. Parrott in this issue). Moreover what is relevant is the phenotype, the effect of the modification, and not the method used for achieving it. It is plausible that different direct

TABLE 2

Kinds of mutation and their advantages/disadvantages

\begin{tabular}{lll}
\hline Origin & Advantages $^{\mathbf{a}}$ & Disadvantages $^{\mathbf{b}}$ \\
\hline Spontaneous mutation & No/little regulation & Low frequency/restricted choice \\
\hline Induced mutation & No/little regulation & Low frequency/restricted choice \\
\hline Mutagenic oligonucl. & Specific, quick, little/no regulation & Restricted choice \\
\hline Transposon & May be specific & May be reversible, single target, low frequency \\
\hline T-DNA insertion & Specific/irreversible & Single target, low frequency \\
\hline Antisense RNA & Specific, dominant, sequence-based, many targets & Silenced gene intact (reversible), may be leaky \\
\hline RNAi (hpRNA) & Specific, dominant, sequence-based, many targets & Silenced gene intact (reversible), may be leaky \\
\hline miRNA & Specific, dominant, sequence-based, many targets & Silenced gene intact (reversible), may be leaky \\
\hline
\end{tabular}

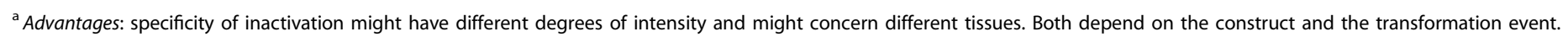

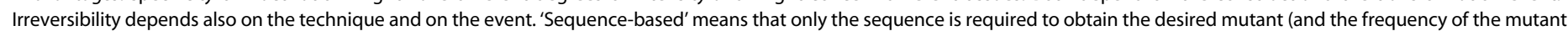
is usually high.

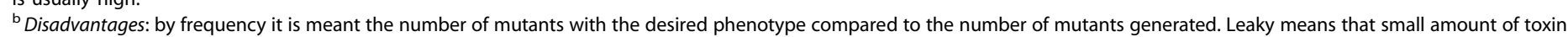
might still be produced (e.g. [63]) in the tissue. 
mutations (e.g. a deletion spanning the whole gene, the insertion of a T-DNA or of a transposon or a point mutation) produce the same effect by affecting a similar target, like, for instance (1) the promoter region (eliminating transcription) or (2) the coding region (introducing an early stop codon or a missense mutation, affecting protein stability, folding or activity) or (3) a splice site (abolishing the splicing) or (4) determinants of mRNA stability (causing rapid mRNA degradation). The extent (length of the DNA involved), nature (insertion, deletion or change) and site of action (transcription, splicing, mRNA stability, translation, protein folding or stability or catalysis) of the mutation can be very different. Similarly for indirect mutations, the origin of the asRNA, its length, position and extent of pairing with the mRNA can vary greatly between different indirect strategies. Also the ultimate level of action for the asRNA can be different: in some cases the duplex formation targets the mRNA for destruction and inhibits translation, in other cases the small RNA fragments can lead to an alteration in the methylation pattern of the gene and ultimately in the silencing of transcription.

\section{No one method suites all situations (of pros and cons)}

Gene inactivation is an excellent means to study gene function and it has been applied to basically all processes in living organisms since the discovery of mutations and their hereditability. More recently, systematic insertional mutagenesis was applied to Arabidopsis (e.g. [53,54,62] and other plants to study gene function in all aspects of their biology. This paper deals only with strategies aiming at inactivating toxin and allergens.

In the case of direct gene inactivation, some methods like X-rays or T-DNA insertion very often cause irreversible mutations which are stably inherited. Both characteristics are obviously advantageous for breeding. Other mutations, caused by chemical mutagens, spontaneous to base change or transposon insertion, might be more prone to reversion and less desirable compared to stable ones. Certain methods (insertional mutagenesis with T-DNA or transposons) are ineffective or slow when multiple gene codings for similar proteins need to be inactivated at the same time. In these cases, approaches like RNAi or antisense are more effective. Another big advantage of this approach is that knowledge of the sequence is the only requirement. Once the target gene is known, the construction of a transgenic organism affected in the expression of the gene is relatively easy. However, in the case of indirect gene inactivation, the target gene remains intact and therefore the phenotype might revert completely when the 'interfering' gene is inactivated or removed. Very interestingly, RNA-based inactivation methods allow for gene inactivation in specific tissues or developmental stages, as well as multiple targets, goals much more difficult (but not impossible in principle) to achieve with other methods.

In short, the best method depends on the specific combination of trait/crop one wants to achieve. The strong regulation required for mutants produced by some method is of course a self-imposed disadvantage that has no scientific basis (see contribution by $\mathrm{H}$. Miller in this issue).

\section{Examples of inactivation of toxins in transgenic plants}

The seed-specific inactivation of the biosynthetic pathway for gossypol is the most striking example of the potential of biotech- nology for toxin inactivation. Sunilkumar et al. [63] cloned a fragment of $\delta$-cadinene synthase, the first step in gossypol biosynthesis, into a hpRNA vector and obtained tissue-specific silencing of the corresponding gene by restricting the expression with the seed-specific $\alpha$-globulin B gene promoter. All transgenic seeds show a strong reduction in the level of gossypol, within the limits approved by the World Health Organization (WHO). The trait strictly co-segregates with the transgene and is stably maintained in the RNAi lines. The levels of gossypol and other protective terpenoids (hemigossypolone and heliocides) in leaves are not altered. Earlier attempts to reduce gossypol via antisense RNA did not yield a strong reduction or were unconvincing (see $[63,64]$ for other references).

The authors demonstrated that it is possible to disrupt gossypol biosynthesis in seeds (and in seeds only) by interfering with the expression of a biosynthetic gene during seed development. Targeted gene silencing can thus be used to modulate biosynthetic pathways in a specific tissue to obtain a desired phenotype. Traditional breeding was unable to achieve this goal. Most remarkably, the authors hope to get reduced-gossypol cotton through regulatory approval process in the U.S., but, due to the very high costs (estimated in the range of $50 \mathrm{M} \$$, see contribution by I. Potrykus in this issue) they 'do not know where the money is going to come from' (K. Rathore, pers. commun.). The foregone benefits of a delay in delivering this variety to farmers are evident with around a billion hungry people on the planet.

Another example is the reduction of glucosinolates in Arabidopsis. Several groups have recently identified regulators of the biosynthetic pathway [65-71]. Overexpression and gene inactivation/silencing studies have revealed that Myb28, 29 and 76 control the aliphatic pathway. Myb28 is responsible for the basal transcription of the biosynthetic genes together with Myb29. Inactivation of the former effectively eliminates long-chain aliphatic glucosinolates, while inactivation of the latter reduces the amount of short-chain glucosinolates. Elimination of both gene functions results in the complete loss of aliphatic glucosinolates. Myb76 seems to be relevant in the induction of the pathway following wounding, but does not play a major role in the basal transcriptional regulation. By contrast, Myb34, 51 and 122 control the aromatic (indolic) branch. There appears to be a complex cross regulation between the two branches because a reduction in flux in one branch stimulates the flux in the other one. Even though Arabidopsis is not a crop, research findings with this species are easily transferred to other brassicas (e.g. [72]). A precise manipulation of glucosinolate content in seeds needs a better understanding of the full regulatory circuitry and transport. As for cotton, seed-specific silencing might be a desirable approach to avoid an overall increase in pest sensitivity.

As a third example there is again cassava. Different transgenic strategies have been attempted to reduce cyanogenic glucosides [73-77]. Antisense inhibition or RNA interference in leaves of the first step of cyanogen biosynthesis reduces linamarin levels by 60 $94 \%$ in leaves and by $99 \%$ in roots. These plants however are impaired in growth or tuber formation in the absence of a reduced nitrogen source, presumably due to the role of cyanogen hydrolysis in aminoacid biosynthesis $[73,77]$. A more promising strategy is expressing the leaf-specific enzyme hydroxynitrile lyase (HNL) in roots to accelerate cyanogenesis and cyanide volatilization 
during processing [74]. Several other examples of reductions of toxin have been published, but they have little relevance to food (nicotine in tobacco [78], morphine in Poppy [79,80]). Of interest is the reduction of antinutritional factors like phytic acid in maize [81] for environmental benefits, even if it decreases germination.

\section{Room for improvement of orphan crops}

Lathyrus sativus is a hardy tropical/subtropical legume also known as grass or Indian pea. Beans from this so-called 'famine crop' are an important source of nutrition for poor people in Asia and Africa, but contain a neurotoxin: oxalyldiamino-propionic acid (ODAP). This compound causes lathyrism, a lower limbs paralytic disease prevalent among adults in Central India who consume large quantities of seeds for several months [82]. Safe content for ODAP is $<0.2 \%$, while content in germplasm ranges between 0.3 and 3.3 [83]. Soaking and boiling of seeds reduce ODAP levels but effective detoxification often results in a decrease of nutritional quality. Classical breeding and tissue culture approaches have already produced varieties with greatly reduced ODAP levels (see references in [84], but the substantial outcrossing rate for this crop means that low ODAP lines must be multiplied in isolation and provided to farmers every year [85]. A biosynthetic pathway has been proposed for ODAP [86] and it is thus feasible to attempt its silencing only in the seed using a transgenic approach, as done for gossypol biosynthesis in cotton. Antisense or RNAi construct, due to their dominance, would reduce the need for segregation in seed production.

Other examples are two millet species, fonio and pearl millet, which are cultivated for food in sub-Saharan Africa and India with an annual production of $22 \mathrm{Mt}$ ( $80 \%$ of the world total). High consumption of these two species is known to cause goiter (see references in [87]) with its burden of suffering [44] due to the flavonoids apigenin and vitexin, respectively in fonio and pearl millet, which are strong inhibitors of thyroid peroxidase. Available knowledge allows one to attempt the targeted inactivation of the biosynthetic pathway in seeds and suggest that genetic engineering approaches are more reasonable than conventional ones [87].

\section{Trade-offs for toxin reduction}

Reduction in toxin content usually comes with a price: plants become more susceptible to pests $[70,71,27,88]$ sometimes to the point of making them unsuitable for cultivation $[49,50]$. Several natural pesticides are quite general in their mode of action [89] and natural pesticides account for $99.99 \%$ of our dietary pesticide intake [90]. For example, benzoxazinones, secondary metabolites from cereals, are important in the defense against insects, fungi and bacteria [91,92] and the same is true for the glucosinolates/ myrosinase system in brassicas [93]. Similarly cyanogenic glucosides seem generally toxic against insects and animals $[11,94,95]$ and protect plants from herbivores $[27,28]$, even though several insects might have evolved specific resistance. On the contrary, accumulating new pesticides into a plant increases pest resistance (e.g. cyanogenic glucosides [96]). This strategy is indeed the key to the success of insect resistance based on Bt toxins engineered into cotton and maize [97], as well as many other species (e.g. [98,99]). The environmental and safety price bargained through the more precise tools of genetic engineering is expected to be substantially lower than those obtained with classical genetic approaches, because of the use of pesticides (e.g. Bt or avidin, see [100]) targeting only specific classes of pests, and a much wiser alternative to the application of synthetic chemicals.

\section{Plant-derived allergens}

Allergens are of widespread occurrence and one might not be aware of their presence until experiencing their effects. It is not only a nuisance and/or a cost, but it could be a deadly threat. Minute amounts of allergens might cause a life-threatening event called an anaphylactic reaction. This might occur after ingestion, skin contact, injection or inhalation of an allergen. In the UK alone, allergens in food are reported to have caused 48 deaths over a 7-year period between 1999 and 2006 [101]. Half of the eight foods accounting for $90 \%$ of all food-allergic reactions (milk, egg, fish, shellfish, peanut, tree nut, soy, and wheat) are of plant origin [102]. Products containing them are quite widespread and difficult to avoid in a standard diet. Beyond them, pollen is the major cause of respiratory allergy, with at least $40 \%$ of type 1 allergic patients who are sensitized against grass pollen allergens.

Contrary to common perception, transgenic plants never caused allergic reactions to consumers. In one case a gene for a $2 S$ albumin from the Brazil nut (a known allergenic food) was expressed in soybean [103]. The resulting transgenic soybean was tested for allergenicity and it was ascertained that the $2 \mathrm{~S}$ albumin is indeed a major Brazil-nut allergen. The development of this product was abandoned, no product was ever commercialized or released and no consumer suffered any allergic reactions. This was not a serendipitous finding, because if a gene used for transgenesis comes from a plant containing allergens, the transgene has to be checked for allergenicity. A similar situation was found for transgenic peas expressing the bean $\alpha$-amylase inhibitor [104]. The transgenic peas elicited an immune response in mice upon feeding, but the reaction could be ascribed to changes induced in the plant by the transformation and regeneration procedure or by the changes detected in the $\alpha$-amylase inhibitor between bean and pea [105] regarding the glycosylation pattern and the removal of amino acid residues of the protein. The guidance rules adopted in the EU require a risk analysis for potential allergenicity for any gene that is being used for transformation $[106,107]$.

\section{Examples of inactivation of allergens in transgenic plants}

There are several examples of manipulations for the reduction of plant allergens content (apple, peanut, wheat, soybean, ryegrass and birch). In this paper I discuss one example each from soybean and apple. Several papers describing or reviewing other cases are available [108-112] (M. Schenk, Birch pollen allergy: molecular characterization and hypoallergenic products, Ph.D. thesis, Wageningen University, 2008 (http://www.library.wur.nl/wda/ dissertations/dis4391.pdf)).

In the US/Europe: $5-8 \%$ of babies and $2 \%$ of adults are reported to be allergic to soybeans. The dominant soybean allergen is a protein named P34 or Gly $\mathrm{m}$ Bd $30 \mathrm{~K}$, with more than $65 \%$ of soysensitive patients reacting only to it. Mutagenesis and breeding allowed the removal of some soybean allergens [113,114], but not the dominant allergen P34. Transgenic soybeans without P34 were readily obtained by gene silencing $[115,116]$. Apart P34, the authors found no difference in composition, development, struc- 
ture, polypeptide pattern or ultrastructure when comparing the silenced line with control plants. However, using the very same words of the authors, 'regulatory difficulties and the lack of acceptance of GM soybeans by the baby food and formula industry makes using such an allergen-suppressed soybean difficult at the present time', a euphemism to mean nearly impossible. Therefore an alternative approach was used to achieve the same goal: identify soybeans lacking the allergen. The entire USDA national soybean germplasm collection was screened and out of more than 16,000 accessions screened, they found 12 lines ( 2 of which are cultivated soybean) with no P34 allergen [117]. Based on the sequence analysis, it is possible to guess the reason why these soybean plants lack the allergen. It is however possible that the expression of many other genes is altered with concomitant unintended effects (e.g. expression of new allergens). By contrast, the suppressed soybean line was thoroughly investigated by 2D gel electrophoresis and the only change detected concerns the targeted polypeptide out of the 1400 examined. Beyond any logic, the approval for the transgenic event will be far more complicated and costly than for the conventional mutant lines (E. Herman, pers. commun.).

Apple allergy is dominated by protein Mal d 1, which is also found in birch pollen. Allergenicity depends on the amount of specific Mal d 1 isoforms, whose quantity varies among apple cultivars. Because of this, classical breeding might be used to create new hypo-allergenic cultivars, but this is complicated by the fact that Mal d 1 is encoded by a gene family comprising at least 18 members (loci) arranged in several gene clusters. The expression of Mal d 1 in apple was inhibited by RNAi [118] and this translated into a reduced in vivo allergenicity. In another study [119], the allelic diversity of the seven Mal d 1 genes was investigated in several apple cultivars. It is clear that few alleles associate strongly with differences in allergenicity, suggesting that the production of new varieties by breeding is a feasible target. However, it takes over 15 years to produce a marketable cultivar out of a cross and therefore the direct production of clones with reduced amount of an allergen by transformation of existing cultivars seems a reasonable shortcut, except for the exorbitantly high hurdles associated with present regulatory regime.

It is often feared in non-scholarly sources that plant biotechnology would inadvertently introduce new allergens in foods. The examples presented here, as well as the available literature, make it clear that biotechnology is part of the solution to allergies rather than a cause of increased concern.

\section{An example of insanity in regulation: percent similarity is not everything}

Biosafety regulations require that if a protein shares at least $35 \%$ identity over 80 amino acids to an allergen, then any transgenic plant or product expressing it must be labeled as 'potential allergen', even if there is no evidence for any allergenicity [107], unless it can be proved that the protein is not an allergen. Phaseolin is a protein from bean which is not recognized as an allergen or listed in the official allergenonline.com website, even if it shares a substantial similarity (53\% identity) to $\beta$-conglycinin, a minor soybean allergen. Moreover phaseolin is safely eaten by around one billion people everyday. The $27 \mathrm{kDa} \gamma$-zein is a storage protein from maize which is also not recognized as allergenic and con- sumed by hundreds of millions of people everyday. Zeolin, a chimera between phaseolin and 89 amino acids of $\gamma$-zein has been produced [120] and expressed in transgenic cassava (C. Fauquet, pers. commun.). However, zeolin-expressing cassava should be labeled as a 'potential allergen' because the similarity of phaseolin to $\beta$-conglycinin is well above the limit and it would be impossible to demonstrate that zeolin cannot be an allergen. Actually it would only be possible, as well as difficult and expensive, to demonstrate that the risk is below a certain level. This cassava shows a $350 \%$ improvement in protein content and a 55\% reduction in cyanogenic glucoside, an unintended but welcome effect. It would be made freely available in developing countries if regulations would allow it. The labeling requirement, an obviously impossible (as well as ridiculous) task in places like Africa, makes this transgenic cassava another victim of present day regulation and a rather enlightening example of its insanity.

To stress the point, let us take an example of poetry (the first verses of Dante's Paradise, Canto I, v. 1-3): ‘The glory of Him who moveth everything/Doth penetrate the universe, and shine/In one part more and in another less.' If we now substitute $40 \%$ of the letters in the words (changes underlined), we could get the following as one of the many examples: The story of him who believeth everything/Does infiltrate diverse lies and causes/one part of farm-

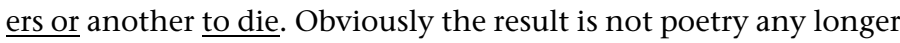
and the meaning is substantially different. A similar thing happens with protein sequences. Two proteins could have $80 \%$ identity and yet perform different functions or have different structures. Conversely, proteins with little or no sequence identity could have similar structures or perform similar functions. The $\%$ of sequence identity is often a poor indicator of the protein properties and it is unreasonable to rely on it for predictions, if other evidence is at hand.

\section{Conclusions}

Plant-derived allergens and toxins are ubiquitous, abundant and essentially unavoidable components of our diet and environment. Tools are available to reduce them at the genetic level, either by conventional or transgenic approaches. However, strategies must be reasonable, that is accept some level of risk, and effective, that is the benefits have to be balanced against cost. For instance, it is unreasonable to require demonstration that zeolin is not an allergen when both phaseolin and zein are not. Similarly, it is unfair to demand multigenerational feeding tests on insect resistance Bt maize but not on maize varieties more resistant to several insects because accumulate more benzoxazinones [121]. Overcautious regulation goes in the opposite directions on both issues: a zero risk tolerance requires endless testing (and infinite costs) to obtain approval for innovative products as substitutes of older technologies. Moreover, reducing the content of natural toxins is often a threshold issue (the dose makes the poison). Accepting low levels of toxins seems a sensible option $[89,90]$ and even a beneficial choice [122].

The insanity of present regulation is more evident with so-called 'loss of function' mutations, that is mutations inactivating gene function, such as many of those mentioned in this review, but similar arguments can be put forward for other kinds of genetic changes. The fact that genetic engineering easily achieved something that conventional breeding was unable to do - for example 
maintain gossypol in leaves, where it is useful, and eliminate it in seeds [63], see also $[123,124]$ - is the demonstration of the higher precision of this technology, not a proof of its unnaturalness, because it is conceivable that screening a larger number of conventional mutants might eventually deliver the same phenotype. An overcautious attitude might kill the technology altogether and its associated benefits. Comparing the techniques adopted for reducing toxins and allergens, usually transgenesis shows superior characteristics: it is not only more efficient in obtaining the desired phenotype (both in time and trial numbers) but also more precise. Natural null mutants for the P34 soybean allergen [117] have a frequency of $2 / 14,000$ in cultivated soybean, that is $0.014 \%$, and the exact reason for the lack of P34 is uncertain. Conversely, the frequency of soybeans coming out of a transformation showing P34 cosuppression is in the 10-20\% range (E. Herman, pers. commun.). The possibility of 'unintended effects' is obviously smaller for the transgenic mutant, because a detailed analysis revealed only one change in composition (one protein missing out of around 1400 examined), the reason of which is the transgene. In other words safety testing of transgenic varieties must be compared against testing of varieties developed by conventional means.

Breeding approaches allowed in the past the creation of new varieties with lower toxin levels: erucic acid and glucosinolates in brassicas [39], cyanogenic glucosides in clover, cassava, almonds and cotton just to name a few $[27,46,49,125,126]$. Transgenesis is another tool which can be employed for the same purpose (e.g. $[63,73])$ and seems particularly suited for reducing the allergenic content of foods and plants in general, especially in fruit trees, where the use of conventional means, like mutagens or crosses among natural variants, is discouraged for practical reasons (e.g. the method takes too long a time or would alter the peculiar characteristics of the cultivar).

Other specific problems still await a solution or optimization. Several legumes must be heat treated before consumption especially for monogastric animals because they contain one or more toxic compounds: trypsin inhibitors, amylase inhibitors and lectins (in legumes [127]), saponins, vicine and convicine (pyrimidine glucosides from broad beans) responsible for favism in humans [128], just to name a few. The possibility of reducing single or multiple toxins in food and feed could improve food safety, food security and conversion efficiency. Other compounds like phytate are not toxic, but reduce availability of phosphate and iron in legumes and, to a lesser extent, in cereals [81]. The evident consequence of this further domestication is the need to substitute general pesticides for new, more specific pesticides like Bt to counter plant pests. Several new plant toxic proteins with insecticidal properties have potential in this respect [129-131] some of which are commonly found in foods we already eat (e.g. [132]) and we know how to inactivate them. A particular appealing strategy is the use of RNAi in plants to silence pest genes $[133,134]$.

Sometimes it could be desirable to modulate the content of specific compounds. Glucosinolate hydrolysis products seem also to be responsible for the anticarcinogenic activity of brassica vegetables in humans [135], but the beneficial dose window of glucosinolate hydrolysis products can be rather narrow. It is amazing how fully acceptable is a new 'superbroccoli' variety obtained by conventional breeding through a cross with a wild variety [136] with a 10-fold increase in a specific glucosinolate content and a 100-fold inducing potency of a marker of phase II detoxification enzymes in mammalian systems. This is obviously considered to be a good thing by the popular press [137]. Another variety, named 'Booster Broccoli ${ }^{\mathrm{TM}}$ ', with a smaller but substantial increase in sulforafane, has just been launched on the market and its purported non-GM status is highlighted together with the benefits of a high sulforafane diet [138]. One wonders what would the reaction be if a transgenic canola (engineered for instance for herbicide tolerance) with minor alteration in glucosinolate profile was to be introduced in the market.

It is conceivable that new almond or peach varieties might accumulate much more cyanogenic glucosides and new potato varieties might accumulate more or new glycoalkaloids. From a few cases in the past [31-35] we know classical breeding can cause problems and yet, in the EU, new varieties with a real toxic potential (e.g. potato) require no regulatory scrutiny (no compulsory measurement of toxic compounds and no safety tests) before release, cultivation or commercialization if they are produced by conventional means. And we also know that conventionally bred crops might present far more changes at the genomic level than transgenic ones [139-144] or might contain new allergens [145]. Therefore there is a strong case for demanding a more science-based regulation (see also contribution by $\mathrm{H}$. Miller in this issue).

Gene technology could further improve food safety, food security and wellbeing as well as reduce environmental impact of agriculture and other human activities. Regulation is a major obstacle because (rewording an Italian common way of saying) 'where logic ends, biotech regulation begins'. Technology is of course a constant source of new problems and challenges as it has been since the beginning of human society. As examples, think of the dangers of moving at high speed or, more recently, the hypothesis that the rise in allergies is linked to a reduced microbial exposure [146]. But rather than reverting to older and less safe technologies, we need to think of more technology as the solution. To state it more humorously in the words of F. Salamini: 'Everybody wants to return to nature, but not by foot'.

\section{Note added in proof}

An interesting approach to insect 'resistance' is reported in Ref. [150].

\section{Acknowledgements}

I thank several colleagues and friends (especially W. Parrott, J. Gressel, D. Kershen, K. Ammann, F. Salamini, G. Fico, A. Vitale, D. Ederle, T. Maggiore, K. Petroni, F. Rossi, G. Succi, L. Gilissen, N. Bisht, K. Rathore, D. Shah, D. Carputo, B. Parisi, C. Faquet, E. Herman, R. Goodman) for support, information, personal communications, help with literature or reviewing the manuscript. Massimo e Monica Delledonne helped by graciously providing a few days of peace. I acknowledge the support of the Scientific Council for Ag-Biotechnology of the Lombardy Region and the University of Milan for access to several books. A particular thanks to I. Potrykus for everything.

I dedicate this paper to Giovanna Ferro-Luzzi and Bruce N. Ames for their inspiring work and examples. 


\section{References}

1 Challoner, K.R. and McCarron, M.M. (1990) Castor bean intoxication: review of reported cases. Ann. Emerg. Med. 19, 1177-1183

2 Viola, S. (1979) Piante medicinali e velenose della flora italiana. De Agostini

3 Burrows, G.E. and Tyrl, R.J. (2006) Handbook of Toxic Plants of North America. Blackwell

4 Hui, Y.H. et al. eds (2001) Foodborne Disease Handbook, Vol. 3, Plant Toxicants, Marcel Dekker Inc

5 EFSA (European Food Safety Authority), (2009) Compendium of botanicals that have been reported to contain toxic, addictive, psychotropic or other substances of concern on request of EFSA. EFSA J. 7, 281 ( http://www.efsa.europa.eu/cs/ BlobServer/External_Rep/esco_compendium_en,0.pdf?ssbinary=true)

6 Stone, S. and King, A. (1997) Know Your Plants. Safe or Poisonous? ( http:// www.plantsciences.ucdavis.edu/ce/king/PoisPlant/)

7 Lazzarini, D. et al. (2006) Food poisoning by Datura stramonium: an unusual case report. Intern. Emerg. Med. 1, 88-90

8 Suk, S.H. and Kwak, Y.T. (2009) Toxic encephalopathy after taking dried seeds of Datura stramonium in two elderly subjects. Geriatr. Gerontol. Int. 9, 326-328

9 Spina, S.P. and Taddei, A. (2007) Teenagers with Jimson weed (Datura stramonium) poisoning. Can. J. Emerg. Med. 9, 467-468

10 Sinden, S.L. and Deahl, K.L. (2001) Alkaloids, in Ref. [4], pp. 247-256

11 Vetter, J. (2000) Plant cyanogenic glycosides. Toxicon 38, 11-36

12 Hansen, A.A. (1925) Two fatal cases of potato poisoning. Science 61, 340

13 Sayre, J.W. and Kaymakcalan, S. (1964) Hazards to health, cyanide poisoning from apricot seeds among children in central Turkey. New Engl. J. Med. 270, 11131115

14 Beier, R.C. and Nigg, H.N. (2001) Toxicology of naturally occurring chemicals in food, in Ref. [4], pp. 37-186

15 London, W.M. (1996) What Comes Naturally: Contaminated Apple Juice and Opposition to Pasteurization. Priorities 8.

16 Greensfelder, L. (2000) Herbal product linked to cancer. Science 288, 1946

17 Kessler, D.A. (2000) Cancer and herbs. New Engl. J. Med. 342, 1742-1743

18 Kingsbury, N. (2009) Hybrid: The History and Science of Plant Breeding. The University of Chicago Press

19 Jadhav, S.J. et al. (1981) Naturally occurring toxic alkaloids in foods. CRC Crit. Rev. Toxicol. 9, 21-104

20 Schmiediche, P.E. et al. (1980) Breeding of the cultivated potato species Solanum juzepczukii Buk., and Solanum curtilobum Juz. et Buk. 1. A study of the natural variation of $S$. juzepczukii, S. curtilobum and their wild progenitor, S. acaule Bitt. Euphytica 29, 685-704

21 Kozukue, N. et al. (2008) Distribution of glycoalkaloids in potato tubers of 59 accessions of two wild and five cultivated Solanum species. J. Agric. Food Chem. 56, $11920-11928$

22 Mithen, R.F. et al. (1987) Glucosinolates of wild and cultivated Brassica species. Phytochemistry 26, 1969-1973

23 Gols, R. et al. (2008) Performance of generalist and specialist herbivores and their endoparasitoids differs on cultivated and wild Brassica populations. J. Chem. Ecol. $34,132-143$

24 Benrey, B. et al. (1998) The effects of domestication of Brassica and Phaseolus on the interaction between phytophagous insects and parasitoids. Biol. Control 11, $130-140$

25 Lucas, B. and Sotelo, A. (1984) Nutr. Rep. Int. 29, 711-719

26 Sotelo, A. et al. (1995) Comparative study of the chemical composition of wild and cultivated beans (Phaseolus vulgaris). Plant Foods Hum. Nutr. 47, 93-100

27 Dirzo, R. and Harper, J.L. (1982) Experimental studies on slug-plant interactions. III. Differences in the acceptability of individual plants of Trifolium repens to slugs and snails. J. Ecol. 70, 101-117

28 Rosenthal, G.A. and Janzen, D.H., eds) (1979) Herbivores: Their Interaction with Secondary Plant Metabolites, Academic Press

29 Mithen, R. et al. (1995) Divergent selection for secondary metabolites between wild populations of Brassica oleracea and its implications for plant-herbivore interactions. Heredity $75,472-484$

30 Lasch, E.E. and El Shawa, R. (1981) Multiple cases of cyanide poisoning by apricot kernels in children from Gaza. Pediatrics 68, 5-7

31 Finkelstein, et al. (1994) An outbreak of phytophotodermatitis due to celery. Int. J. Dermatol. 33, 116-118

32 Berkley, et al. (1986) Dermatitis in grocery workers associated with high natural concentrations of furanocoumarins in celery. Ann. Intern. Med. 105, 351-355

33 Herrington, M.E. (1983) Intense Bitterness in Commercial Zucchini. Cucurbit Genetics Cooperative Report 6. pp. 75-76 ( http://www.cuke.hort.ncsu.edu/cgc/cgc06/ cgc6-38.html)
34 Browning, S. and Hodges, L. (2005) Bitterness in Zucchini Squash and Cucumber. Cucumber Crop Information. ( http://www.cuke.hort.ncsu.edu/cucurbit/cuke/ cukehndbk/cukebitterness.html)

35 Anonymous, (1970) Name of potato variety Lenape withdrawn. Am. J. Potato Res. 47,103

36 Sharma, A. et al. (2006) Bottle gourd poisoning. J. Med. Educ. Res. 8, 120-121

37 Gressel, J. (2008) Transgenics are imperative for biofuel crops. Plant Sci. 174, 246263

38 Tripathi, M.K. and Mishra, A.S. (2007) Glucosinolates in animal nutrition: a review. Anim. Feed Sci. Technol. 132, 1-27

39 UFOP (Union for the Promotion of Oil), (2008) Background Paper on Quality Improvement of Rapeseed Meal concerning the Glucosinolate Content. http:// www.ufop.de/downloads/Rapeseed_meal_UFOP_OVID.pdf

40 Ernesto, M. et al. (2002) Persistent konzo and cyanogen toxicity from cassava in northern Mozambique. Acta Trop. 82, 357-362

41 Tylleskar, T. et al. (1993) Konzo: a distinct disease entity with selective upper motor neuron damage. J. Neurol. Neurosurg. Psychiatry 56, 638-643

42 Cardoso, P.A. et al. (2004) Combination of cassava flour cyanide and urinary thiocyanate measurements of school children in Mozambique. Int. J. Food Sci. Nutr. 55, 183-190

43 Oluwole, O.S. et al. (2003) Incidence of endemic ataxic polyneuropathy and its relation to exposure to cyanide in a Nigerian community. J. Neurol. Neurosurg. Psychiatry 74, 1417-1422

44 Hetzel, B.S. (1989) The Story of Iodine Deficiency. Oxford University Press

45 Balyejusa Kizito, E. et al. (2007) Quantitative trait loci controlling cyanogenic glucoside and dry matter content in cassava (Manihot esculenta Crantz) roots. Hereditas 144, 129-136

46 Nhassico, D. et al. (2008) Rising African cassava production, diseases due to high cyanide intake and control measures. J. Sci. Food Agric. 88, 2043-2049

47 EFSA (European Food Safety Authority), (2008) Gossypol as undesirable substance in animal feed - scientific opinion of the panel on contaminants in the food chain. EFSA J. 908, 1-55 ( http://www.efsa.europa.eu/EFSA/efsa_locale1178620753812_1211902297879.htm)

48 Zhang, W.J. et al. (2006) Optimization of process parameters for reduction of gossypol levels in cottonseed meal by Candida tropicalis ZD-3 during solid substrate fermentation. Toxicon 48, 221-226

49 Bottger, G.T. et al. (1964) Relationship of gossypol content of cotton plants to insects resistance. J. Econ. Entomol. 57, 283-285

50 Jenkins, J.N. et al. (1966) The comparative preference of insects for glanded and glandless cottons. J. Econ. Entomol. 59, 352-356

51 Weil, C. and Martienssen, R. (2008) Epigenetic interactions between transposons and genes: lessons from plants. Curr. Opin. Genet. Dev. 18, 188-192

52 Kapitonov, V.V. and Jurka, J. (2007) Helitrons on a roll: eukaryotic rolling-circle transposons. Trends Genet. 23, 521-529

53 Wisman, E. et al. (1998) The behaviour of the autonomous maize transposable element En/Spm in Arabidopsis thaliana allows efficient mutagenesis. Plant Mol. Biol. 37, 989-999

54 Alonso, J.M. et al. (2003) Genome-wide insertional mutagenesis of Arabidopsis thaliana. Science 301, 653-657

$55 \mathrm{Li}$, C. et al. (2006) Rice domestication by reducing shattering. Science 311, 19361939

56 Konishi, S. et al. (2006) An SNP caused loss of seed shattering during rice domestication. Science 312, 1392-1396

57 Sang, T. (2009) Genes and mutations underlying domestication transitions in grasses. Plant Physiol. 149, 63-70

58 Burger, J.C. et al. (2008) Molecular insights into the evolution of crop plants. Am. J. Bot. $95,113-122$

59 Eamens, A. et al. (2008) RNA silencing in plants: yesterday, today, and tomorrow. Plant Physiol. 147, 456-468

60 Mansoor, S. et al. (2006) Engineering novel traits in plants through RNA interference. Trends Plant Sci. 11, 559-565

61 Schwab, R. et al. (2006) Highly specific gene silencing by artificial microRNAs in Arabidopsis. Plant Cell 18, 1121-1133

62 Sessions, A. et al. (2002) A high-throughput Arabidopsis reverse genetics system. Plant Cell 14, 2985-2994

63 Sunilkumar, G. et al. (2006) Engineering cottonseed for use in human nutrition by tissue-specific reduction of toxic gossypol. Proc. Natl. Acad. Sci. U. S. A. 103 18054-18059

64 Townsend, B.J. and Llewellyn, D.J. (2007) Reduced terpene levels in cottonseed add food to fiber. Trends Biotechnol. 25, 239-241 
65 Hirai, M.Y. et al. (2007) Omics-based identification of Arabidopsis Myb transcription factors regulating aliphatic glucosinolate biosynthesis. Proc. Natl. Acad. Sci. U. S. A. 104, 6478-6483

66 Sønderby, I.E. et al. (2007) A systems biology approach identifies a R2R3 MYB gene subfamily with distinct and overlapping functions in regulation of aliphatic glucosinolates. PLOS ONE 2, e1322

67 Gigolashvili, T. et al. (2007) The R2R3-MYB transcription factor HAG1/MYB28 is a regulator of methionine-derived glucosinolate biosynthesis in Arabidopsis thaliana. Plant J. 51, 247-261

68 Gigolashvili, T. et al. (2007) The transcription factor HIG1/MYB51 regulates indolic glucosinolate biosynthesis in Arabidopsis thaliana. Plant J. 50, 886-901

69 Gigolashvili, T. et al. (2008) HAG2/MYB76 and HAG3/MYB29 exert a specific and coordinated control on the regulation of aliphatic glucosinolate biosynthesis in Arabidopsis thaliana. New Phytol. 177, 627-642

70 Beekwilder, J. et al. (2008) The impact of the absence of aliphatic glucosinolates on insect herbivory in Arabidopsis. PLoS ONE 3, e2068

71 Malitsky, S. et al. (2008) The transcript and metabolite networks affected by the two clades of Arabidopsis glucosinolate biosynthesis regulators. Plant Physiol. 148, 2021-2049

72 Østergaard, L. et al. (2006) Pod shatter-resistant Brassica fruit produced by ectopic expression of the FRUITFULL gene. Plant Biotechnol. J. 4, 45-51

73 Siritunga, D. and Sayre, R.T. (2003) Generation of cyanogen-free transgenic cassava. Planta 217, 367-373

74 Siritunga, D. et al. (2004) Overexpression of hydroxynitrile lyase in cassava roots accelerates cyanogenesis and detoxification. Plant Biotechnol. J. 2, 37-43

75 Taylor, N. et al. (2004) Development and application of transgenic technologies in cassava. Plant Mol. Biol. 56, 671-688

76 Siritunga, D. and Sayre, R.T. (2004) Engineering cyanogen synthesis and turnover in cassava. Plant Mol. Biol. 56, 661-669

77 Jørgensen, K. et al. (2005) Cassava plants with a depleted cyanogenic glucoside content in leaves and tubers. Distribution of cyanogenic glucosides, their site of synthesis and transport, and blockage of the biosynthesis by RNA interference technology. Plant Physiol. 139, 363-374

78 Lewis, R.S. et al. (2008) RNA interference (RNAi)-induced suppression of nicotine demethylase activity reduces levels of a key carcinogen in cured tobacco leaves. Plant Biotechnol. J. 6, 346-354

79 Allen, R.S. et al. (2004) RNAi-mediated replacement of morphine with the nonnarcotic alkaloid reticuline in opium poppy. Nat. Biotechnol. 22, 1559-1566

80 Kempe, K. et al. (2009) RNAi suppression of the morphine biosynthetic gene salAT and evidence of association of pathway enzymes. Phytochemistry 70, 579 589

81 Shi, J. et al. (2007) Embryo-specific silencing of a transporter reduces phytic acid content of maize and soybean seeds. Nat. Biotechnol. 25, 930-937

82 Barceloux, D.G. (2009) Grass pea and neurolathyrism (Lathyrus sativus L.). Dis. Mon. 55, 365-372

83 Mustafa, A.E.M.A. et al. (2007) Evaluation of Lathyrus spp. germplasm for quality traits. J. Biol. Sci. 7, 1339-1346

84 Vaz Patto, M. et al. (2006) Lathyrus improvement for resistance against biotic and abiotic stresses: from classical breeding to marker assisted selection. Euphytica 147, 133-147

85 Yadav, S.S. and Bejiga, G. (2006) Lathyrus sativus L. record from protabase. In PROTA (Plant Resources of Tropical Africa/Ressources végétales de l'Afrique tropicale) (Brink, M. and Belay, G., eds), Wageningen ( http://www.database.prota.org/ search.htm)

86 Yan, Z.Y. et al. (2006) Lathyrus sativus (grass pea) and its neurotoxin ODAP Phytochemistry 67, 107-121

87 Gressel, J. (2008) Swollen necks from fonio millet and pearl millet. In Genetic Glass Ceilings: Transgenics for Crop Biodiversity. JHU Press pp. 325-331

88 Steppuhn, A. et al. (2004) Nicotine's defensive function in nature. PLoS Biol. 2, E217

89 Ames, B.N. et al. (1990) Nature's chemicals and synthetic chemicals: comparative toxicology. Proc. Natl. Acad. Sci. U. S. A. 87, 7782-7786

90 Ames, B.N. et al. (1990) Dietary pesticides (99.99\% all natural). Proc. Natl. Acad. Sci. U. S. A. 87, 7777-7781

91 Niemeyer, H.M. (2009) Hydroxamic acids derived from 2-hydroxy-2H-1,4benzoxazin-3(4H)-one: key defense chemicals of cereals. J. Agric. Food Chem. 57, 1677-1696

92 Sicker, D. et al. (2000) Role of natural benzoxazinones in the survival strategy of plants. Int. Rev. Cytol. 198, 319-346

93 Raybould, A.F. and Moyes, C.L. (2001) The ecological genetics of aliphatic glucosinolates. Heredity 87, 383-391

94 Zagrobelny, M. et al. (2004) Cyanogenic glucosides and plant-insect interactions Phytochemistry 65, 293-306
95 Montgomery, R.D. (1980) Cyanogens. In Toxic Constituents of Plant Foodstuff (Liener, I.E., ed.), pp. 143-160, Academic Press

96 Tattersall, D.B. et al. (2001) Resistance to an herbivore through engineered cyanogenic glucoside synthesis. Science 293, 1826-1828

97 Sanvido, O. and Romeis, J. (2007) Ecological impacts of genetically modified crops: ten years of field research and commercial cultivation. Adv. Biochem. Eng./ Biotechnol. 107, 235-278

98 Driver, J. et al. (2004) Transgenic trap crops and rootstocks show potential. Calif. Agric. 58, 96-97

99 Snow, A.A. et al. (2003) A Bt transgene reduces herbivory and enhances fecundity in wild sunflowers. Ecol. Appl. 13, 279-286

100 Kramer, K.J. et al. (2000) Transgenic avidin maize is resistant to storage insect pests. Nat. Biotechnol. 18, 670-674

101 Pumphrey, R.S. and Gowland, M.H. (2007) Further fatal allergic reactions to food in the United Kingdom, 1999-2006. J. Allergy Clin. Immunol. 119, 1018-1019

102 Clare Mills, E.N. and Shewry, P.R. (2005) Plant Food Allergens. Wiley-Blackwell

103 Nordlee, J.A. et al. (1996) Identification of a Brazil-nut allergen in transgenic soybeans. New Engl. J. Med. 334, 688-692

104 Prescott, V.E. et al. (2005) Transgenic expression of bean alpha-amylase inhibitor in peas results in altered structure and immunogenicity. J. Agric. Food Chem. 53, 9023-9030

105 Chen, H. et al. (2009) Unintended changes in protein expression revealed by proteomic analysis of seeds from transgenic pea expressing a bean alpha-amylase inhibitor gene. Proteomics 9, 4406-4415

106 EFSA, (2006) Guidance document of the Scientific Panel on Genetically Modified Organisms for the risk assessment of genetically modified microorganisms and their derived products intended for food and feed use. EFSA J. 374, 1-115 ( http:// www.efsa.europa.eu/EFSA/efsa_locale-1178620753820_1211902600026.htm)

107 Goodman, R.E. et al. (2008) Allergenicity assessment of genetically modified crops - what makes sense? Nat. Biotechnol. 26, 73-81

108 Dodo, H.W. et al. (2008) Alleviating peanut allergy using genetic engineering: the silencing of the immunodominant allergen Ara $\mathrm{h} 2$ leads to its significant reduction and a decrease in peanut allergenicity. Plant Biotechnol. J. 6, 135-145

109 Petrovska, N. et al. (2004) Transgenic ryegrasses (Lolium spp.) with downregulation of main pollen allergens. Mol. Breed. 14, 489-501

110 Le, L.Q.et al. (2006) Design of tomato fruits with reduced allergenicity by dsRNAimediated inhibition of ns-LTP (Lyc e 3) expression. Plant Biotechnol. J. 4, 231-242

111 Gilissen, L.J.W.J. et al. (2008) Beyond coeliac disease toxicity. Detoxified and non-toxic grains. In Frontiers in Celiac Disease. Pediatr. Adolesc. Med. (Fasano, A. and Troncone, R., eds), pp. 139-147, Karger

112 Singh, M.B. and Bhalla, P.L. (2008) Genetic engineering for removing food allergens from plants. Trends Plant Sci. 13, 257-260

113 Samoto, M. et al. (1997) Substantially complete removal of three major allergenic soybean proteins Gly m Bd $30 \mathrm{~K}$, Gly $\mathrm{m}$ Bd $28 \mathrm{~K}$ and the alpha-subunit of conglycinin from soy protein by using a mutant soybean, Tohoku 124 . Biosci. Biotechnol. Biochem. 61, 2148-2150

114 Ogawa, T. et al. (2000) Soybean allergens and hypoallergenic soybean products. J. Nutr. Sci. Vitaminol. 46, 271-279

115 Herman, E.M. et al. (2003) Genetic modification removes an immunodominant allergen from soybean. Plant Physiol. 132, 36-43

116 Herman, E. (2005) Soybean allergenicity and suppression of the immunodominant allergen. Crop Sci. 45, 462-467

117 Joseph, L.M. et al. (2006) Evaluation of glycine germplasm for nulls of the immunodominant allergen P34/Gly m Bd 30k. Crop Sci. 46, 1755-1763

118 Gilissen, L.J.W.J. et al. (2005) Silencing the major apple allergen Mal d 1 by using the RNA interference approach. J. Allergy Clin. Immunol. 115, 364-369

119 Gao, Z. et al. (2008) Assessment of allelic diversity in intron-containing Mal d 1 genes and their association to apple allergenicity. BMC Plant Biol. 8, 116

120 Mainieri, D. et al. (2004) Zeolin. A new recombinant storage protein constructed using maize gamma-zein and bean phaseolin. Plant Physiol. 136, 3447-3456

121 Barry, D. et al. (1994) Relation of European corn borer (Lepidoptera: Pyralidae) leaf-feeding resistance and DIMBOA content in maize. Environ. Entomol. 23, 177182

122 Calabrese, E.J. (2008) Hormesis: why it is important to toxicology and toxicologists. Environ. Toxicol. Chem. 27, 1451-1474

123 Frick, S. et al. (2007) Metabolic engineering with a morphine biosynthetic P450 in opium poppy surpasses breeding. Metab. Eng. 9, 169-176

124 Travella, S. et al. (2006) RNA interference-based gene silencing as an efficient tool for functional genomics in hexaploid bread wheat. Plant Physiol. 142, 6-20

125 Boulter, G.S. (1983) The history and marketing of rapeseed oil in Canada. In High and Low Erucic Acid Rapeseed Oils. Production, Usage, Chemistry, and Toxicological Evaluation (Kramer, J.K.G., Sauer, F.D., Pidgen, W.J., eds), pp. 62-83, Academic Press 
126 Sánchez-Pérez, R. et al. (2008) Bitterness in almonds. Plant Physiol. 146, 1040-1052

127 Lajolo, F.M. and Genovese, M.I. (2002) Nutritional significance of lectins and enzyme inhibitors from legumes. J. Agric. Food Chem. 50, 6592-6598

128 Farran, M.T. et al. (2002) Vicine and convicine in common vetch (Vicia sativa) seeds enhance beta-cyanoalanine toxicity in male broiler chicks. Int. J. Toxicol. 21, 201-209

129 Carlini, C.R. and Grossi-de-Sá, M.F. (2002) Plant toxic proteins with insecticidal properties. A review on their potentialities as bioinsecticides. Toxicon 40, 1515 1539

130 Stepek, G. et al. (2007) Nematicidal effects of cysteine proteinases against sedentary plant parasitic nematodes. Parasitology 134, 1831-1838

131 Craveiro, K.I. et al. (2009) Variant Cry1Ia toxins generated by DNA shuffling are active against sugarcane giant borer. J. Biotechnol. 145, 215-221

132 Solleti, S.K. et al. (2008) Transgenic cowpea (Vigna unguiculata) seeds expressing a bean alpha-amylase inhibitor 1 confer resistance to storage pests, bruchid beetles. Plant Cell Rep. 27, 1841-1850

133 Huang, G. et al. (2006) Engineering broad root-knot resistance in transgenic plants by RNAi silencing of a conserved and essential root-knot nematode parasitism gene. Proc. Natl. Acad. Sci. U. S. A. 103, 14302-14306

134 Gordon, K.H. and Waterhouse, P.M. (2007) RNAi for insect-proof plants. Nat. Biotechnol. 25, 1231-1232

135 Traka, M. et al. (2008) Broccoli consumption interacts with GSTM1 to perturb oncogenic signalling pathways in the prostate. PLOS ONE 3, e2568

136 Mithen, R. et al. (2003) Development of isothiocyanate-enriched broccoli, and its enhanced ability to induce phase 2 detoxification enzymes in mammalian cells. Theor. Appl. Genet. 106, 727-734

137 BBC (2000) Super-broccoli 'to fight cancer'. News 24 May. (http:// www.news.bbc.co.uk/2/hi/health/762425.stm)

138 Booster broccoli (2009) (http://www.vitalvegetables.com.au/consumer/boosterbroccoli.html)
139 Batista, R. et al. (2008) Microarray analyses reveal that plant mutagenesis may induce more transcriptomic changes than transgene insertion. Proc. Natl. Acad. Sci. U. S. A. 105, 3640-3645

140 Baudo, M.M. et al. (2006) Transgenesis has less impact on the transcriptome of wheat grain than conventional breeding. Plant Biotechnol. J. 4, 369380

141 Cheng, K.C. et al. (2008) Effect of transgenes on global gene expression in soybean is within the natural range of variation of conventional cultivars. J. Agric. Food Chem. 56, 3057-3067

142 Catchpole, G.S. et al. (2005) Hierarchical metabolomics demonstrates substantial compositional similarity between genetically modified and conventional potato crops. Proc. Natl. Acad. Sci. U. S. A. 102, 14458-14462

143 Shewry, P.R. et al. (2007) Are GM and conventionally bred cereals really different? Trends Food Sci. Technol. 18, 201-209

144 Baudo, M.M. et al. (2009) Establishing substantial equivalence: transcriptomics. Methods Mol. Biol. 478, 247-272

145 Kleter, G.A. and Peijnenburg, A. (2003) Presence of potential allergy-related linear epitopes in novel proteins from conventional crops and the implication for the safety assessment of these crops with respect to the current testing of genetically modified crops. Plant Biotechnol. J. 1, 371-380

146 Tse, K. and Horner, A.A. (2008) Allergen tolerance versus the allergic march: the hygiene hypothesis revisited. Curr. Allergy Asthma Rep. 8, 475-483

147 Egber, A. (1998) Creating aversion to giant fennel (Ferula communis) in weaned orphaned lambs. Appl. Anim. Behav. Sci. 61, 51-62

148 Arnett, A.M. (1995) Jimson weed (Datura stramonium) poisoning. Clin. Toxicol. Rev. 18 (Available at: http://www.erowid.org/plants/datura/datura_info5.shtml)

149 Snyman, T. et al. (2001) A fatal case of pepper poisoning. Forensic Sci. Int. 124, 4346

150 Kater, M.M. et al. (2003) The use of floral homeotic mutants as a novel way to obtain durable resistance to insect pests. Plant Biotechnol. J. 1, 123-127 